\title{
11.1
}

\section{Эксперимент по созданию канала радиосвязи в морской среде}

\author{
(C) А.К. Томилин ${ }^{1}$, А.Ф. Лукин ${ }^{2}$, А.Н. Гульков ${ }^{2}$ \\ ${ }^{1}$ Национальный исследовательский Томский политехнический университет, Томск, Россия \\ ${ }^{2}$ Дальневосточный федеральный университет, Владивосток, Россия \\ E-mail: aktomilin@tpu.ru
}

Поступило в Редакцию 14 января 2021 г.

В окончательной редакции 10 марта 2021 г.

Принято к публикации 15 марта 2021г.

\begin{abstract}
Описан натурный эксперимент по передаче коротковолнового модулированного радиосигнала в морской среде при помощи шаровых антенн на расстояние $470 \mathrm{~m}$. Специальная приемопередающая аппаратура сконструирована в соответствии с результатами обобщенной электродинамической теории. Сделано предположение о возможности создания канала высокочастотной радиосвязи в морской среде посредством продольных электромагнитных волн.
\end{abstract}

Ключевые слова: радиосвязь в морской среде, обобщенная электродинамика, шаровая антенна.

DOI: 10.21883/PJTF.2021.11.51009.18710

Проблемы создания наземных беспроводных каналов радиосвязи успешно решены более ста лет назад, однако этого нельзя сказать о связи с автономными подводными объектами. Это объясняется значительным затуханием высокочастотных поперечных электромагнитных волн в электропроводной среде. Использование сверхнизких частот ограничено необходимостью применения крупногабаритных антенн и недостаточной скоростью передачи данных $[1,2]$. Для контактов с мобильными подводными объектами часто применяется гидроакустическая связь, которая также обладает существенными недостатками $[3,4]$.

В настоящее время развивается обобщенная электродинамическая теория, учитывающая как вихревые, так и потенциальные электромагнитные процессы [5-9]. Экспериментально обнаружена потенциальная компонента магнитного поля, которую описывает скалярная функция индукции $B^{*}(\mathbf{r}, t)$. Определены условия возникновения потенциального магнитного поля и его свойства. Построена теория комплексной электромагнитной волны, описывающая ее как последовательность вихревых и потенциальных процессов. В результате вихревых процессов возникают поперечные электромагнитные волны, определяемые векторами $\mathbf{E}_{\text {rot }}$ и Н. Потенциальные процессы генерируют продольные электромагнитные волны, для описания которых используются скалярный потенциал электрического поля $\phi(\mathbf{r}, t)$ и скалярная функция $B^{*}(\mathbf{r}, t)$. Поскольку электрический потенциал определяет потенциальное электрическое поле $\left(\mathbf{E}_{\text {grad }}=-\nabla \phi\right)$, продольные электромагнитные волны принято называть электроскалярными (или скалярно-продольными) [7-9].

Цель настоящей работы - экспериментальная проверка возможности создания канала коротковолновой радиосвязи на продольных волнах в морской среде.

Чтобы технически осуществить радиосвязь в морской среде, нужно создать нестационарное сферическисимметричное электрическое поле с высокой напряжен- ностью. Это возможно за счет явления безвихревой электромагнитной индукции [5-9], которое описывается дифференциальным уравнением

$$
\nabla \cdot \mathbf{E}_{\text {grad }}=\frac{\rho}{\varepsilon_{0} \varepsilon^{\prime}}+\frac{\partial B^{*}}{\partial t} .
$$

Из уравнения (1) следует, что потенциальное электрическое поле можно генерировать не только при помощи электрических зарядов плотности $\rho$, но и за счет нестационарного потенциального магнитного поля, которое создает квазизаряд плотности $\varepsilon_{0} \varepsilon^{\prime} \partial B^{*} / \partial t$. В монографии [5] описаны эксперименты, подтверждающие этот феномен.

Реализовать технически эту идею можно с помощью плоской спиральной катушки Тесла при пропускании по ней нестационарного тока $[5,8,9]$. В ее центре создается нестационарный квазизаряд высокой плотности. Если центр катушки соединить с металлической сферой, то на ней возникнет потенциал $\phi(t)$, изменяющийся с большой амплитудой. Это позволяет создать вокруг сферы сильное потенциальное электрическое поле. Оно является нестационарным и имеет радиальную структуру.

На основе теории, изложенной в монографии [5], разработана методика расчета параметров приемопередающей аппаратуры, изготовлены экспериментальные образцы (рис. 1). Катушка Тесла диаметром $320 \mathrm{~mm}$ имеет 27 витков медного провода диаметром $2 \mathrm{~mm}$. Центральный виток катушки соединен металлической штангой с медным шаром диаметром $60 \mathrm{~mm}$. На вход передающей антенны подается сигнал с выхода радиостанции „Штурман-882M“ на частоте $27.4 \mathrm{MHz}$, модулированный по амплитуде частотой „тонального вызова“, спектр которого находится в полосе частот около 498-511 Hz. Мощность радиостанции на излучение составляет $1.17 \mathrm{~W}$. Действующее высокочастотное напряжение на выходе передатчика при работе на реальную нагрузку составляет $7.66 \mathrm{~V}$. Действующая сила тока 


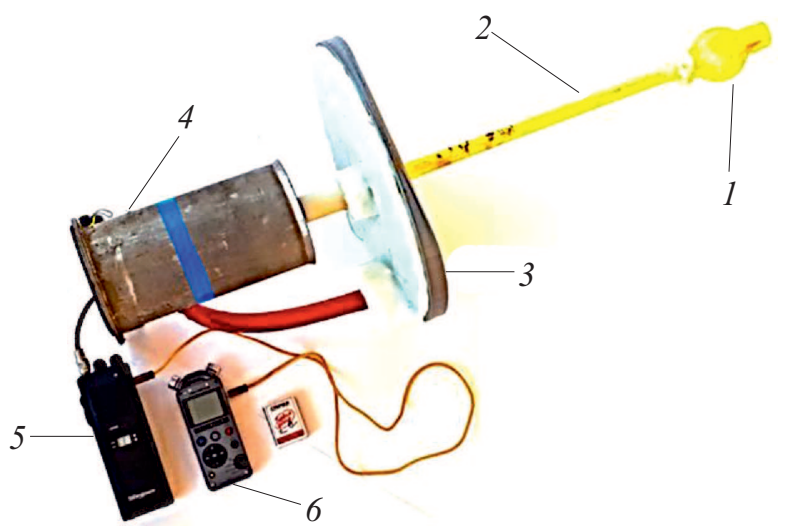

$a$

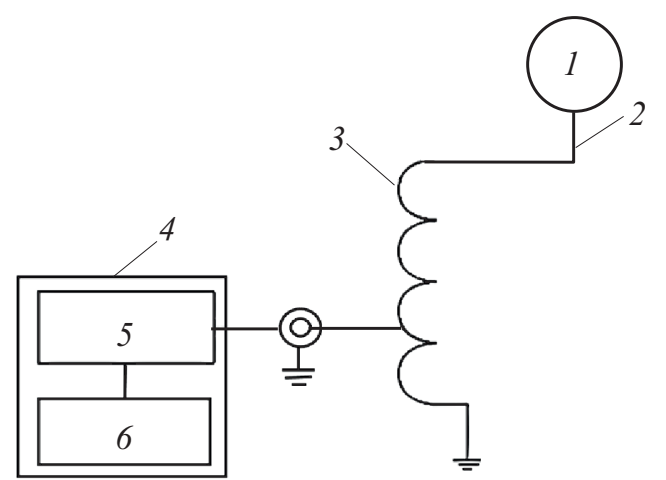

Рис. 1. Экспериментальный образец приемной станции $(a)$ и ее электрическая схема $(b) .1$ - сфера из меди (антенна), $2-$ штанга, 3 - катушка Тесла, 4 - герметичный металлический бокс, 5 - радиостанция, 6 - цифровой диктофон.

в катушке $0.15 \mathrm{~A}$. В результате трансформации в катушке Тесла амплитуда высокочастотного напряжения на шаровой антенне составляет примерно $45 \mathrm{~V}$. Это соответствует нестационарному заряду, изменяющемуся с амплитудой $12.5 \cdot 10^{-9} \mathrm{C}$, который генерируется на медном излучающем шаре, находящемся в водной среде.

Радиостанция вместе с батареями электропитания помещена в герметичный бокс, жестко сопряженный с антенной. Все элементы антенны изолированы слоем диэлектрика от контакта с морской водой. Приемная станция имеет аналогичную конструкцию. В ней сигнал модуляции с разъема наушников радиостанции подается на вход диктофона „Olympus LS-12“, размещенного в герметичном боксе.

Проведена серия экспериментов с постепенным увеличением дальности передачи сигнала. В работе представлены данные об испытаниях, которые проводились 27 октября 2020г. во Владивостоке, в бухте Новик (остров Русский). Приемная станция была установлена на заякоренном буе на глубине $6 \mathrm{~m}$. Глубина моря в этом месте составляет $13 \mathrm{~m}$. Проводимость морской воды в районе испытаний $4.77 \mathrm{~S} / \mathrm{m}$. Температура воды $+8^{\circ} \mathrm{C}$. Как приемная, так и передающая станция опускались в воду на капроновых фалах, не имеющих металлических частей. Этим обеспечивалась полная электромагнитная автономность обоих модулей в погруженном состоянии. Передающая станция была полностью погружена в морскую среду и находилась на глубине $4 \mathrm{~m}$ от поверхности моря. С 9-й по 40-ю минуту передающая станция равномерно буксировалась катером по направлению от приемного модуля. Расстояние между станциями измерялось с помощью GPS-приемника.

Записанный на диктофон сигнал обрабатывался с использованием спектрального анализа в окне длительностью $30 \mathrm{~s}$ с шагом окна $7.5 \mathrm{~s}$ с весовым окном Гаусса. Рассчитана средняя мощность сигнала „тонального вызова“ для модулирующего сигнала (MC) передающей радиостанции в полосе частот $498-511 \mathrm{~Hz}$, приведенная к полосе частот $1 \mathrm{~Hz}$. Для сравнения в полосе частот $515-520 \mathrm{~Hz}$, где отсутствовали компоненты частот сиг- нала „тонального вызова“ фоновых шумов (МФ), также приведенная к полосе частот $1 \mathrm{~Hz}$. Спектральный анализ записи на диктофон сигнала от калиброванного и поверенного звукового генератора позволил пересчитать уровни МС и МФ в $\mathrm{dB}$ относительно уровня мощности $1 \mu \mathrm{W}$, приведенной к полосе частот $1 \mathrm{~Hz}$. Полученные результаты в зависимости от времени эксперимента представлены на рис. 2.

Приемный модуль находился в морской воде с 9-й по 43-ю минуту записи. Расстояние между передающим и приемным модулями изменялось от $20 \mathrm{~m}$ на 9-й минуте записи до максимального $470.7 \mathrm{~m}$ на 40-й минуте. Средний уровень МС за время протяжки поддерживался пределах от -87 до $-88 \mathrm{~dB}$ в результате работы автоматической регулировки усиления в приемной радиостанции. Средний уровень МФ за это же время изменялся в пределах от -95 до $-93 \mathrm{~dB}$. Таким образом, зафиксированный в эксперименте уровень превышения МС над уровнем МФ составил 5-8 dB относительно $1 \mu \mathrm{W}$ в полосе частот $1 \mathrm{~Hz}$.

С нулевой по 9-ю минуту записи и с 43-й по 46-ю минуту записи передающий модуль оставался в морской воде, а приемный модуль был на борту катера. В эти

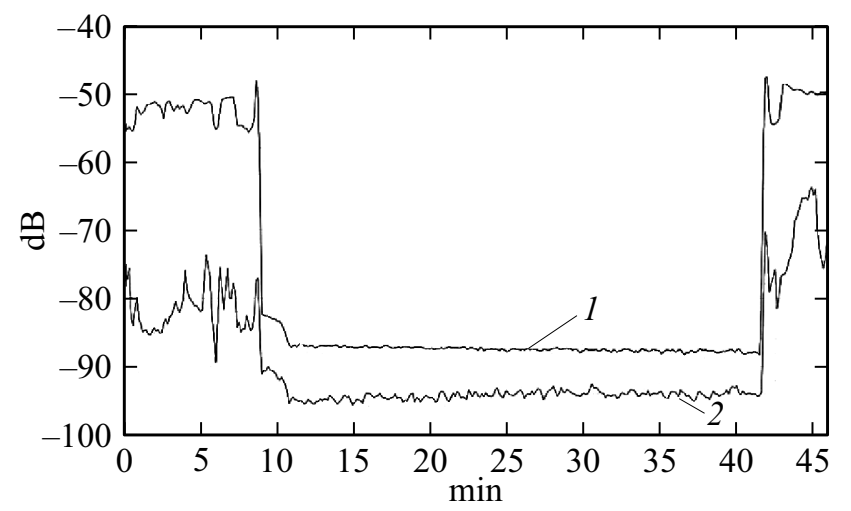

Рис. 2. Средняя мощность принимаемого сигнала (1) и фоновых шумов (2) относительно мощности $1 \mu \mathrm{W}$, приведенной к полосе частот $1 \mathrm{~Hz}$. 
периоды времени уровень МС изменялся в пределах от -48 до $-55 \mathrm{~dB}$. При этом уровень МФ изменялся в пределах от -74 до $-89 \mathrm{~dB}$ до начала протяжки и от -64 до $-81 \mathrm{~dB}$ после ее окончания. Таким образом, был зафиксирован факт уверенной передачи сигнала из воды в воздух при распространении радиосигнала на расстояние $4 \mathrm{~m}$ в воде и около $3 \mathrm{~m}$ в воздухе с превышением уровня МС над уровнем МФ на $20 \mathrm{~dB}$ и более. В других экспериментах также была зафиксирована передача радиосигнала из воздушной среды в морскую.

Расчетное затухание уровня мощности радиосигнала для поперечных волн на расстоянии $1 \mathrm{~m}$ в морской среде с проводимостью $4.77 \mathrm{~S} / \mathrm{m}$ на частоте $27.4 \mathrm{MHz}$ составляет около $195 \mathrm{~dB} / \mathrm{m}$. Для расстояния $470 \mathrm{~m}$ суммарное затухание должно составлять около $91650 \mathrm{~dB}$, что многократно превышает запас помехоустойчивости используемых радиостанций. Однако канал подводной радиосвязи на этом расстоянии реально работает. Следовательно, можно предположить, что радиосигнал передается в морской воде при помощи продольных (электроскалярных) волн.

Таким образом, экспериментально в натурных условиях доказана возможность создания канала высокочастотной радиосвязи в морской среде. Предположительно это происходит с использованием электроскалярных волн. Обнаружен эффект передачи высокочастотного радиосигнала через границу раздела двух сред: морская вода-воздух.

\section{Благодарности}

Теория и техника эксперимента, а также результаты испытаний неоднократно обсуждались на рабочих совещаниях с участием специалистов из АО „Корпорация „Московский институт теплотехники“ (Москва) и ПАО „Дальприбор“ (Владивосток). Авторы выражают благодарность сотрудникам этих организаций за поддержку и полезные советы.

\section{Финансирование работы}

Работа выполнена в рамках программ повышения конкурентоспособности ТПУ и ДВФУ.

\section{Конфликт интересов}

Авторы заявляют, что у них нет конфликта интересов.

\section{Список литературы}

[1] В.Г. Максименко, Радиотехника и электроника, 65 (2), 141 (2020). DOI: 10.31857/S0033849420020138

[2] Г.Я. Шайдуров, Г.Н. Романова, Д.С. Кудинов, Радиотехника и электроника, 65 (8), 757 (2020). DOI: $10.31857 / \mathrm{S} 0033849420070116$
[3] В.П. Федосов, С.П. Тарасов, В.В. Воронин, С.В. Кучерявенко, П.П. Пивнев, А.А. Легин, А.В. Ломакина, В.А. Франц, Сети связи для подводных автономных роботизированных комплексов (Изд-во ЮФУ, Ростов н/Д-Таганрог, 2018).

[4] С.В. Душин, С.С. Шаврин, В.С. Алешин, М.П. Фархадов, DSPA: Вопр. применения цифровой обработки сигналов, 10 (2), 11 (2020).

[5] А.К. Томилин, Обобщенная электродинамика (Триумф, M., 2020). DOI: 10.32986/978-5-93673-270-6-2020-04

[6] A.K. Tomilin, in Progress in Electromagnetics Research Symp.-Spring (PIERS) (St. Petersburg, 2017), p. 1414. DOI: 10.1109/PIERS.2017.8261969

[7] Е.И. Нефедов, Электромагнитные поля и волны (Академия, М., 2014).

[8] L.M. Hively, Systems, apparatuses, and methods for generating and/or utilizing scalar-longitudinal waves. Patent US $9306527 B 1$ (Apr. 5, 2016) [Электронный ресурс]. Режим доступа: https://patents.google.com/patent/US9306527B1/en

[9] D. Reed, L.M. Hively, Symmetry, 12 (12), 2110 (2020). DOI: $10.3390 /$ sym 12122110 